Article

\title{
Lighting System Modernization as a Source of Green Energy
}

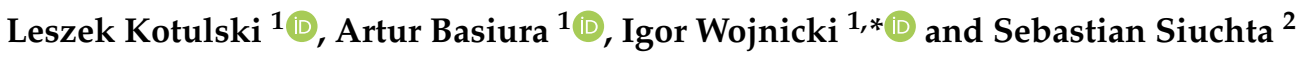 \\ 1 Department of Applied Computer Science, AGH University of Science and Technology, al. Mickiewicza 30, \\ 30-059 Kraków, Poland; kotulski@agh.edu.pl (L.K.); abasiura@agh.edu.pl (A.B.) \\ 2 GRADIS Ltd., ul. Jasnogórska 9B, 31-358 Kraków, Poland; sebastian.siuchta@gradis.pl \\ * Correspondence: wojnicki@agh.edu.pl; Tel.: +48-508-444-450
}

check for

updates

Citation: Kotulski, L.; Basiura, A.; Wojnicki, I.; Siuchta, S. Lighting System Modernization as a Source of Green Energy. Energies 2021, 14, 2771 https://doi.org/10.3390/en14102771

Academic Editor: Jean-Michel Nunzi

Received: 25 March 2021

Accepted: 27 April 2021

Published: 12 May 2021

Publisher's Note: MDPI stays neutral with regard to jurisdictional claims in published maps and institutional affiliations.

Copyright: (C) 2021 by the authors. Licensee MDPI, Basel, Switzerland. This article is an open access article distributed under the terms and conditions of the Creative Commons Attribution (CC BY) license (https:/ / creativecommons.org/licenses/by/ $4.0 /)$.

\begin{abstract}
The use of formal methods and artificial intelligence has made it possible to automatically design outdoor lighting. Quick design for large cities, in a matter of hours instead of weeks, and analysis of various optimization criteria enables to save energy and tune profit stream from lighting retrofit. Since outdoor lighting is of a large scale, having luminaires on every street in urban areas, and since it needs to be retrofitted every 10 to 15 years, choosing proper parameters and light sources leads to significant energy savings. This paper presents the concept and calculations of Levelized Cost of Electricity for outdoor lighting retrofit. It is understood as cost of energy savings, it is in the range from 23.06 to $54.64 \mathrm{EUR} / \mathrm{MWh}$, based on real-world cases. This makes street and road lighting modernization process the best green "energy source" if compared with the 2018 Fraunhofer Institute cost of electricity renewable energy technologies ranking. This indicates that investment in lighting retrofit is more economically and ecologically viable than investment in new renewable energy sources.
\end{abstract}

Keywords: computer aided design; graph transformations; green energy; levelized cost of electricity

\section{Introduction}

The European Union's energy policy includes the need for secure energy supplies, sustainable energy consumption, lower fossil fuel dependence and improvements in energy efficiency. The Fraunhofer Institute [1] showed the levelized costs of electricity (LCOE) for different electricity sources in 2018 and its prediction up to 2035. The LCOE of onshore wind turbines rangeds between 39.9 EUR/MWh and 82.3 EUR/MWh in 2018. As a result, PV systems and onshore wind turbines are, on average, the least expensive technologies in Germany, both among renewable energy technologies as well as fossil fuel power plants. The LCOEs for other sources are as follows:

- $\quad$ photo-voltaic (PV) systems-from 37.1 to 115.4 EUR/MWh,

- $\quad$ offshore wind turbines-from 74.9 to 137.9 EUR/MWh,

- biogas power plants-from 101.4 to 147.4 EUR/MWh,

- conventional power plants:

- $\quad$ brown coal-from 45.9 to $79.8 \mathrm{EUR} / \mathrm{MWh}$,

- $\quad$ hard coal-from 62.7 to $98.6 \mathrm{EUR} / \mathrm{MWh}$,

- combined cycle power plants-from 77.8 to $99.6 \mathrm{EUR} / \mathrm{MWh}$,

- $\quad$ PV home storage systems - from 163.4 to 473.4 EUR/MWh; both the costs of electricity generation and storage.

The United Nations Environment Programme (UNEP) [2] estimates that replacing globally all the inefficient on-grid lighting today would result in 1044 TWh of electricity savings annually, which is equivalent to over USD 120 billion in electricity bills avoided and over $530 \mathrm{Mt}$ of $\mathrm{CO}_{2}$ avoided emissions annually. Our goal is to estimate the cost and savings of the local outdoor lighting retrofit actions performed by cities; it will be calculated as levelized cost of electricity $\left(L C O E_{\text {retrofit }}\right)$. Street and road lighting luminaries 
must be replaced every 10 to 15 years due to their lifespan limit. A retrofit is replacing old luminaries with new ones on the same poles using existing power lines. Optionally arms might be replaced as well due to their lifespan limit or technical reasons regarding luminary mounts. A simple exchange of the luminaries gives at least $40 \%$ reduction of energy consumption due to light source upgrade, from high pressure sodium (HPS) to light emitting diodes (LED). On top of that, there are some examples that proper, optimized design allows increasing this reduction up to $81 \%$ [3].

We consider such proper designs for number of cases which are: two metropolises, Washington DC, USA, and Tbilisi, Georgia, and six other cities in Poland for which the LCOE will be calculated, in this paper. The detailed scope is as follows:

- state of the art of the outdoor lighting systems design,

- theoretical background of Artificial Intelligence (AI) tools supporting large-scale design to achieve optimization,

- basic assumptions on the outdoor lighting in Washington DC and Tbilisi and final parameters of optimal designs,

- analysis of high-quality, optimized designs for six Polish cities; the selection is based on a total of a few hundreds lighting designs for retrofits in smaller cities, each design having less than 10 thousand light points, performed in 2020 for which the total installed power before retrofit was known,

- calculation of $\angle C O E$ for above designs,

- the prediction of LCOE for consecutive years.

Our hypothesis is that upgrading outdoor lighting by using optimized designs and LEDs as light sources could lead to energy savings high enough that such a process would be more economically and ecologically viable than investment in new renewable energy sources. Analysis of such a hypothesis is possible due to technological advancements in lighting design, which enables finding optimized settings for light-point parameters quickly and at large scale.

\section{Outdoor Lighting Design, State of the Art}

To assess $L C O E$, some information regarding the infrastructure and cost have to be acquired:

1. the area has to be chosen and parametrized in terms of light poles and installed power-it is usually carried out by the installation owner;

2. a retrofit efficiency has to be evaluated, with assumptions regarding durability-it is actual lighting design provided by a lighting engineer, specialized company or luminary vendor;

3. cost of replacing a single luminary with assessment of price trends-it should be provided by a luminary vendor;

4. transmission losses-carried out by the installation owner.

Items 2 and 3 represent a proper lighting design, which has a major influence on the LCOE calculation.

The lighting design is a compromise between the safety of road users, the energy cost, and negative health effects, such as light pollution. There are well-established lighting standards to provide safety, such as EN-13201 in EU or similar ANSI/IES RP-8 in USA; however it is up to the lighting designer to optimize energy usage or decrease light pollution.

For many years, lighting designers were only supported by systems that could verify the correctness of the prepared photo-metric designs, e.g., industry standard tools like Dialux or Relux $[4,5]$. The design was based on the human intuition, which allows the designer to assign the current lighting situation, describing actual geometric and technical properties of the area under consideration to one of the established, precalculated patterns or templates. For example, the spacing of consecutive poles at distances $(27,29,28,30) \mathrm{m}$ will be approximated with their maximum, which is a single value of $30 \mathrm{~m}$. It results in $(30,30,30,30)$ spacing. Adopting the maximum spacing of poles guarantees compliance 
with the lighting standards; however, it decreases energy efficiency, and incrases the power of the lighting installation. To ensure that the final design complies with the EN-13201 lighting standard, designers similarly overestimate values of other parameters, such as: road width, pole distance from the street etc. Such simplifications reduce design time. A serious drawback of this approach, however, is the reduced energy efficiency implied by the conservative assumptions on road and lighting installation layout.

There are even more simplifications being used. Values of particular geometric parameters are often grouped into certain "buckets", with some tolerance. For example, a lighting situation with a single lane road with a width between 3 and $4 \mathrm{~m}$ and pole heights between 7 and $8 \mathrm{~m}$, spacing between 26 and $33 \mathrm{~m}$, etc. requires a certain type of luminaries and power setting. Thus, one uses a set of predefined, precalculated templates, which can be widely applied to multiple areas for which the lighting design is to be provided. This matches lighting situations for which a design has already been calculated.

Yet another simplification is associated with the road lighting class. The lighting class tells how much light is needed in order to make the street safe for both vehicle and pedestrian traffic. Its identification is based on a set of parameters, which values might be subjective.

Despite these simplifications, the human-made design process is extremely timeconsuming. For example, a relatively small project in Kraków, Poland with 3768 luminaries took experienced designers 7 weeks to complete. Summarizing, low human productivity makes preparation of standard compliant, energy- and cost-optimized designs for large areas impossible in reasonable time without proper next-generation, computerized tools.

The importance of optimal design increases when we realize that it is not only a way of achieving economic optimization but also has a significant impact on the way of tackling climate changes and improving quality of life.

Fortunately, recent research regarding reduction of this problem's computational complexity makes it possible to obtain high-quality, optimized designs. This is thanks to graph-based representation of computational problems, application of multi-agent systems and distributed processing.

There is also active research regarding outdoor lighting investment planning and decision support [6-8]. This indicates that proper planning increases economic viability of such endeavors significantly. It also confirms that one of the key elements is a standardcompliant design assessed by experts. On the other hand, one of the challenges is competing criteria such as energy consumption, habits, satisfaction [9], or aesthetics. The latter one plays an important role, especially if the investment regards historical or recreational sites. (This is based on GRADIS commercial experience with infrastructure owner requirements.) The competing criteria are also significant in terms of balance between lighting equipment price and luminary power, especially if the vendor contractual price lists fluctuate, which is common. (This is based on GRADIS commercial experience with cost estimates and retail.)

Similarly, retrofit planning also has a significant impact in the case of indoor lighting [10]; however, it is out of scope of this paper.

\section{AI Tools Supporting Large-Scale Design}

As was mentioned earlier, lighting designers have been supported by verification software such as Dialux or Relux [4,5] for some time now. The main goal of such software is to verify if the design prepared by a human designer complies with the given lighting standard. There are more and more successful approaches to apply Artificial Intelligence (AI) for lighting design to change this.

In general, lighting design is an optimization problem with multiple dimensions and degrees of freedom. The dimensions come from actual physical properties of the area under consideration. The degrees of freedom are requirements imposed by the infrastructure owner or investor. In the simplified model, we have to consider $2.75 \times 10^{22}$ combinations of parameter values, which would take the computer system hundreds of years to compute. (This takes into account variability of parameter values, which is based on analysis of actual 
designs such as fixture models, types and powers, tilt angles, arm lengths, pole heights, pole distances from the street, distances between poles, fixture alignment shifts, lamp arrangements, lighting classes, surface types, number of lanes, street widths, sidewalks widths, lighting classes and distances from the street.) Fortunately, there is certain semantics of the data on top of that, which might help in the process of computational complexity reduction.

There are therefore two aspects of the lighting design: knowledge and computation. Knowledge regards actual data on infrastructure-widths, heights, locations, geometries, speed limits, qualitative and quantitative requirements, etc.- while computation provides optimization, which is guided by the former.

Some new approaches use genetic algorithms [11-14] or neural networks [15] to process knowledge and find a high-quality, close-to-optimal design. However, these methods usually have a problem with computational efficiency: preparing a design for a single street segment takes a few hours, which renders them not applicable in practice. Other more promising approaches [16,17] combine formal methods and AI, which results in both high-quality designs and a short computation time. Such an approach is used to calculate $L C O E_{\text {retrofit }}$ as presented in this paper. The game-changing achievement, which has sped up computations, is the use of formal methods that apply mathematical concepts to computer science to turn them into practical applications. Graph transformations, for the specification of the relationship among the input parameters for the design, especially seem to provide a proper framework. If we formalize the design process as a $T$ graph transformation system, the number of the generated graphs that represent actual lighting design parameters $L(T)$ can be significantly lesser than a combination of all possible parameter values. Such an approach reduces the state space that needs to be searched in order to provide the actual design. Any graph $G \in L(T)$ represents the parameters of a correct lighting situation, compliant with the lighting standard, for which it is easy to select an optimal design then $[16,17]$. There are two major challenges:

- to develop a graph transformation mechanism that enables correct and effective design specification-the $T$ graph transformation system,

- to discover the computation methods that speed up the consistency verification of graphs that belong to $L(T)$ according to the EN-13201 standard.

Both of them are addressed in the next subsections.

\subsection{Specification of Correct Lighting Situations}

One can observe that a human usually splits a complex problem into a few subproblems, solves it separately and merges the results. We use this idea to improve designer efficiency in the specification of the outdoor lighting system. In the case of the graph grammar, we prepare a separate specification for each of the sub-problems. This is a case of Dual Graph Grammars [18]. For example, let us consider the modeling and execution of the dynamic lighting control case. In addition to the actual lighting design mentioned earlier, there are two independent hardware layers which require adequate representation and handling through a uniform knowledge base, namely the sensors and luminaries. The sensor layer dynamically gathers the data necessary for lighting class identification. To provide adaptive control, the luminaries must be able to adjust light level to match actual needs. All the adjustments have to comply with the lighting standards, so the design has to reflect additional luminary power settings to enable it.

Data about luminaries, street segment, and traffic intensity detectors have to be properly represented and aggregated. For example, to calculate actual traffic intensity, the placement of the detectors hast to be taken into consideration. They could be doubled or tripled at the same lane, which is a common case, and they could be placed before or after an intersection. In the case presented Figure 1, in order to calculate the traffic intensity $d t$ in segment $s 1$, one needs to perform:

$$
d t=\max (d t 1, d t 3)+\max (d t 2,(d t 4+d t 5))
$$


If we consider a single graph grammar [19], further dynamic control of lighting systems create unintuitive graph structure (like the one in Figure 2), in which logical relationships among the detectors are not shown. Separation of the structure and evaluation into a pair of graph grammars $[\Psi, \Theta]$ (Figures 3 and 4) results in clear model and enhances further processing efficiency since different algorithms, suitable for particular grammars, can be used. The logical model in Figure 3 represented as a $\Psi$ grammar is similar to the one in Figure 2 with one major difference: only one sensor of a given type is associated with each lighting segment, a traffic detector in this case $(d v t / d v t 1)$. The $\Theta$ grammar represents the evaluation of data from the sensors in a form of a mathematical expression syntax tree; see Figure 4 . Synchronization of both graph grammars is called the Dual Graph Grammar mechanism [18]. The overall model $([\Psi, \Theta])$ becomes more intuitive, and the graph processing becomes faster (a benchmarked speed up by 2.8 times). What is more, the Dual Graph grammar concept can be generalized in practice to a set of pairwise synchronized graph transformations.

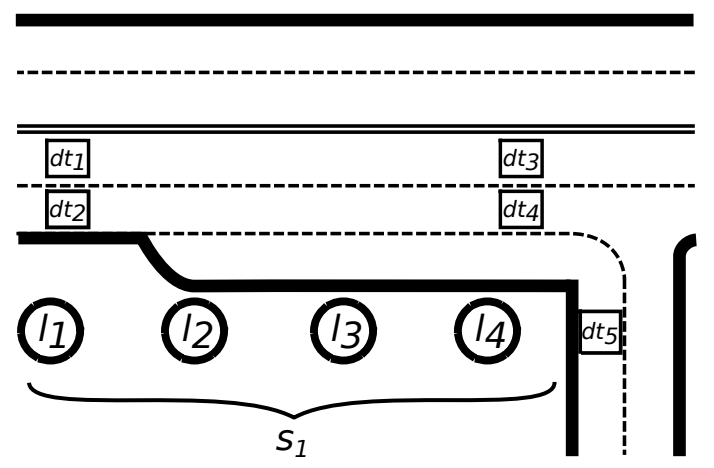

Figure 1. A street segment $s 1$, with luminaires $l 1, \ldots, l 4$ and multiple traffic intensity detectors $d t 1, \ldots, d t 5$.

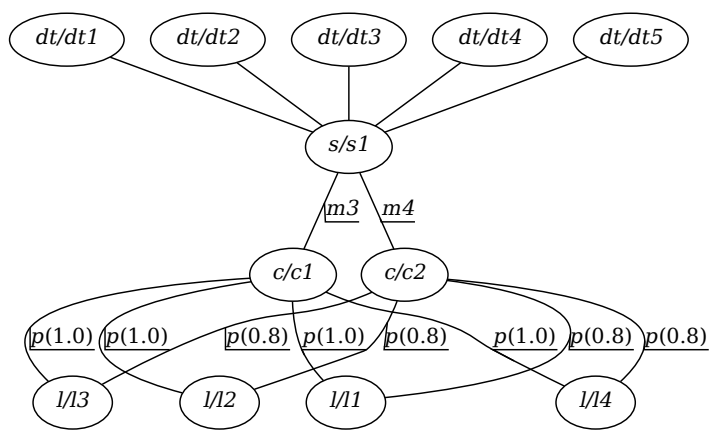

Figure 2. A street segment, single logical model with unclear relationship among the detectors.

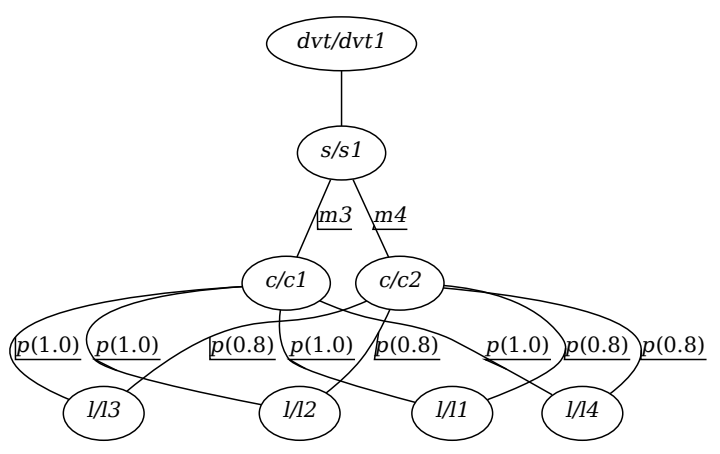

Figure 3. A street segment, logical model, structure grammar $\Psi$. 


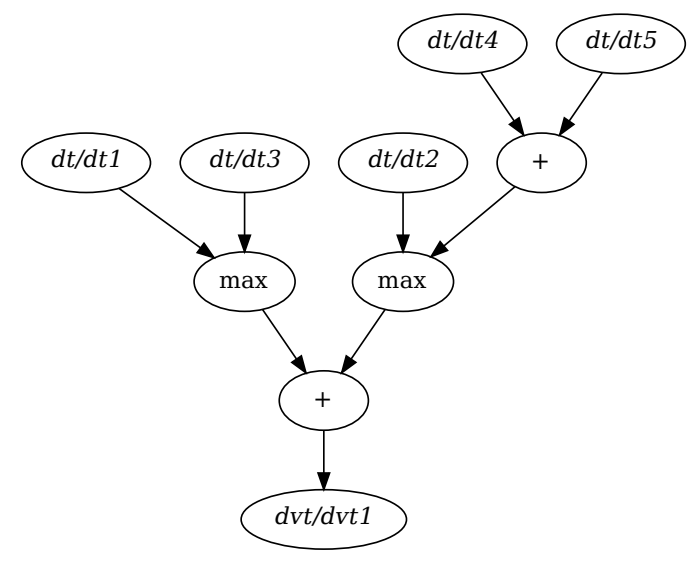

Figure 4. A street segment, logical model, evaluation grammar $\Theta$.

\subsection{Improvement of the Calculation Time}

Let us note that an attempt to optimize the efficiency of the lighting system is in contradiction with the speed of the calculations. In 2016, a modern LED system with dynamic reduction of the lighting level, when the traffic intensity decreases, as it is defined in EN-13201 standard, was applied in a district of Krakow (3768 luminaries), Poland. The final efficiency of this solution was $81 \%$ energy consumption reduction (16\% resulted from the dynamic control application). These calculations were made by optimizing homogeneous sections of street segments. The averaged values for parameters within the segments were used. The calculations took about one hour. We will refer to this method as the standard method. To achieve maximum energy savings, we can split these uniform segments into smaller ones and use more precise methods to obtain better results [20]. This gives us significant $12 \%$ energy savings based on photometry design, and in the rest of document, we will refer to it as the custom method. Unfortunately, the calculation takes 68 times longer [21]. The challenge is to achieve maximum energy savings and perform calculations in a reasonable amount of time.

One of the methods that we can use to dynamically choose the best option (time vs. performance) is to model lighting infrastructure as Infrastructure Abstract Graph (IAG). Based on its graph grammar, we can split it into different size sub-graphs. These sub-graphs can be optimized using different methods, suitable for each of them [21].

For example, we can store a street layout as an IAG, as is shown in Figure 5. It is modeled as four segments (S). There is a series of lamps (CL) and light points (L) in each segment. Depending on the goal, we can optimize it using standard method-in this case, we are not interested in information about particular light points but about a series of lamps (shown in Figure 6). Alternatively, we can use methods that give much better results but cost much more processing time. An example is the discussed custom method. In such a case, we are not interested in a series of lamps (shown in Figure 7) but particular light points. The first method is the best if the installation parameters are similar to each other (e.g., the same pole height, similar distances between poles, etc.). The results can be obtained in a short period of time, and they are just as accurate as the ones obtained by using the custom method. The second method is used if there is heterogeneity in the segment and the segments are small. In such situations, we obtain better optimization; however, the computation time is, as mentioned above, several times longer. The mentioned graph transformations apply not only to graph structures but also optimization criteria. Therefore, based on one graph, we can obtain different sets of solutions for various problems that we can easily compare. 

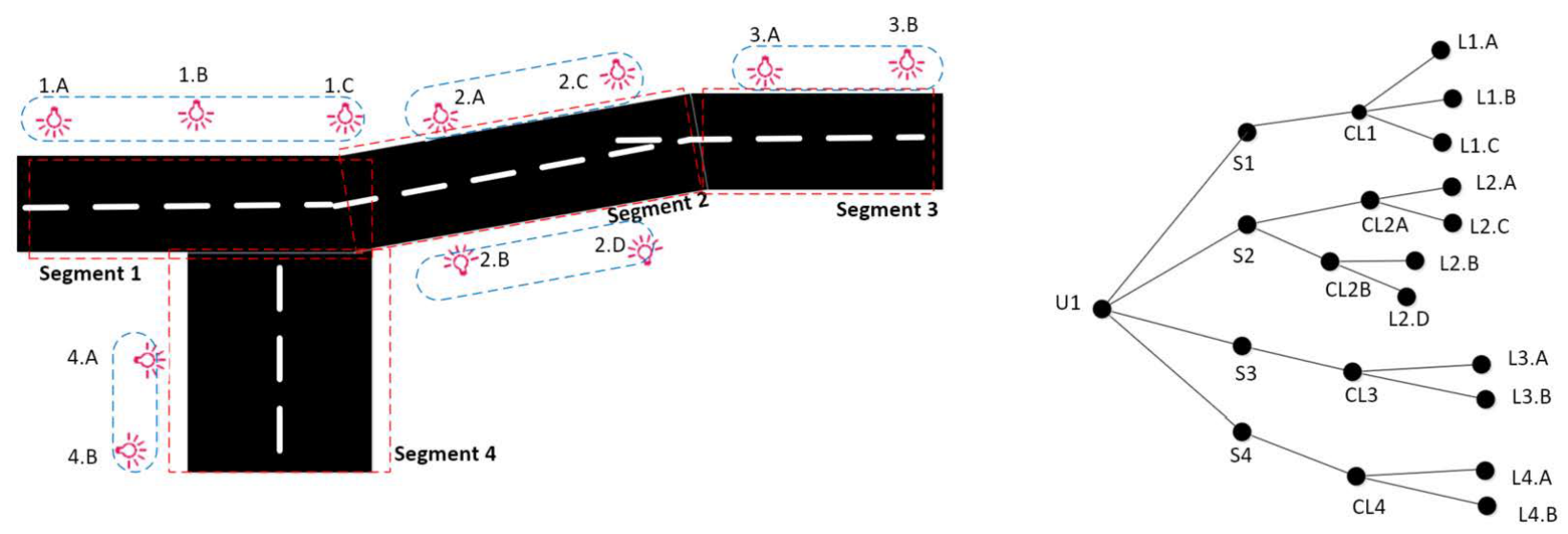

Figure 5. A graph storing information about road lavout.
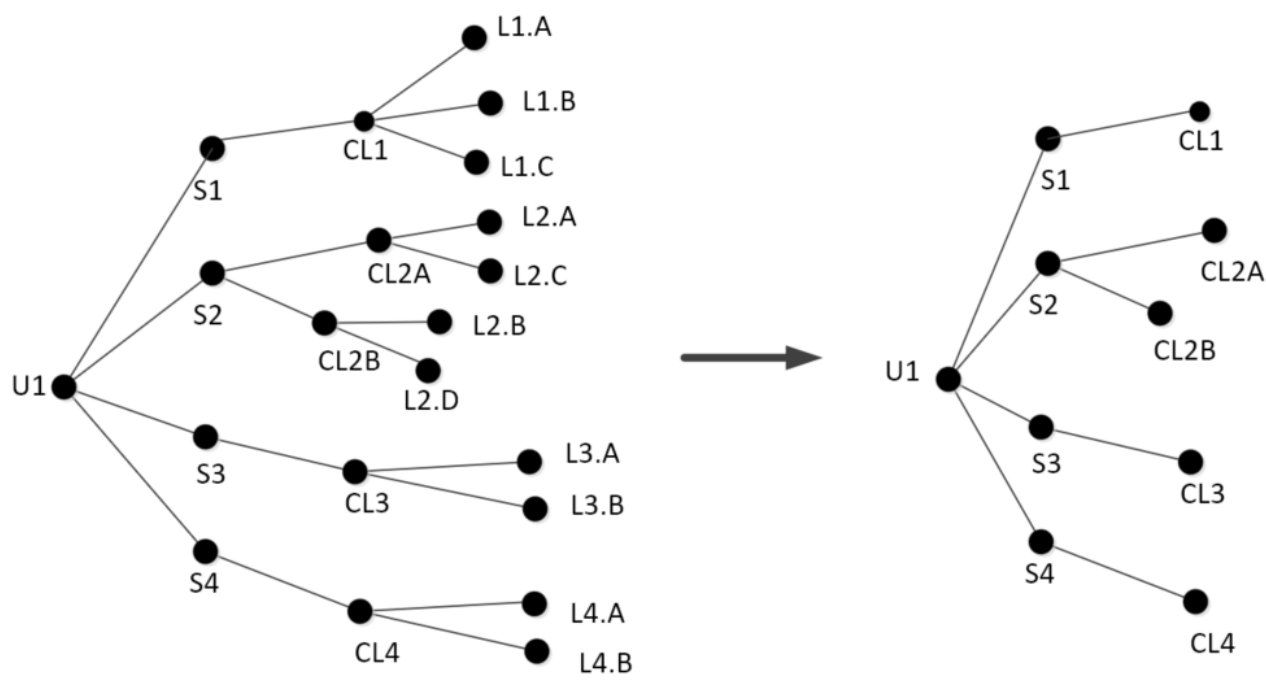

Figure 6. Transformation IAG Graph to graph that can be used for the standard approach.
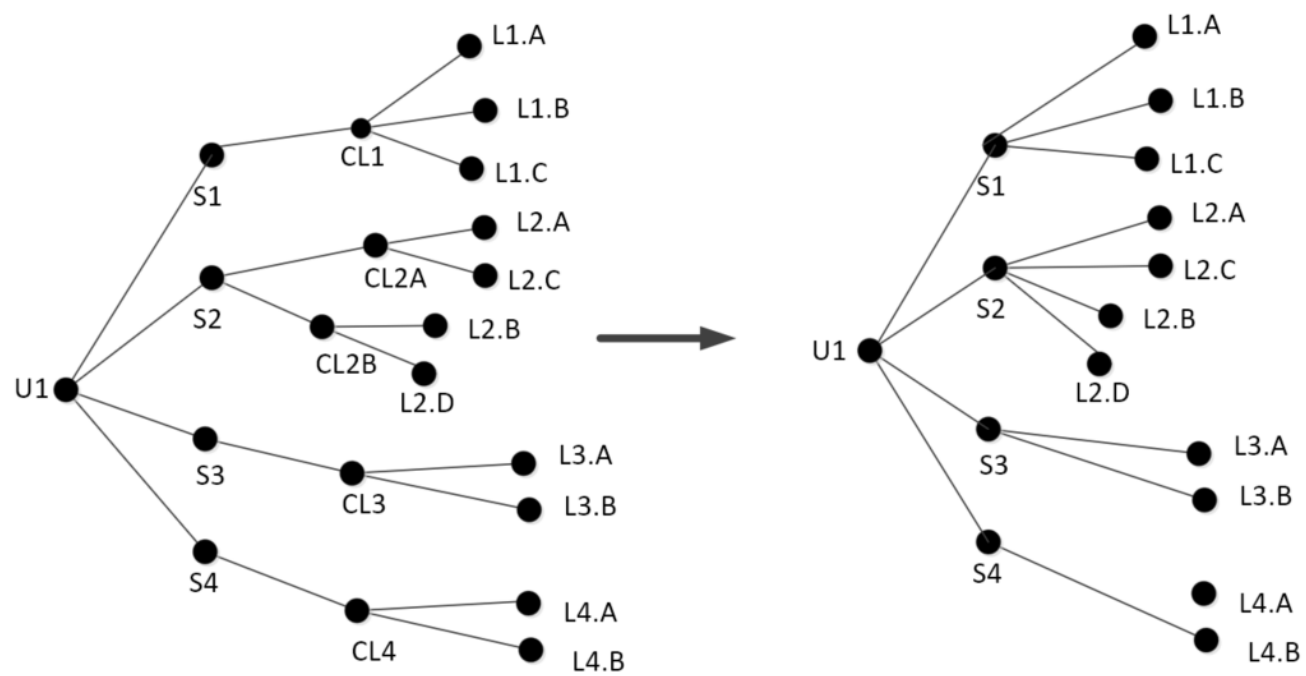

Figure 7. Transformation IAG Graph to graph that can be used for the custom method.

Our goal is to consider more than one optimization criterion and more than one luminary vendor, so we generate a set of final IAG graphs, enabling decision makers to choose the most convenient one. For large segments, we try to find similar graphs and use 
their results as a starting point of the optimization process to reduce computation time. Since the calculation time shifts from days to hours (see Table 1), multiple variants of the design, for multiple vendors or different additional requirements, can be delivered easily.

Table 1. Comparison of processing times in the presented model and without.

\begin{tabular}{ccc}
\hline & Standard Computation & Graph Model \\
\hline Number of segments & 606 & 606 \\
\hline Average computation time for one segment & $5 \mathrm{~min} 25 \mathrm{~s}$ & $6 \mathrm{~min} 14 \mathrm{~s}$ \\
\hline Computation time for all segments & $55 \mathrm{~h} 25 \mathrm{~min}$ & $3 \mathrm{~h} 52 \mathrm{~min}$ \\
\hline $\begin{array}{c}\text { Acceleration of calculations after } \\
\text { applying the graph model }\end{array}$ & & \\
\hline
\end{tabular}

At the implementation level, the cooperation of different calculation subsystems is based on the multi-agent concept $[8,22,23]$. Despite the division of the problem into cooperating subsystems, particular sub-graphs are large. Thus, the Complementary Graphs concept is used. It automatically splits the graph into several parts (partially replicated) and defines the implicit mechanism of the parallel execution of the graph transformations [24]. This concept introduces parallel computation free of human (programmers) interference $[8,22,23,25]$.

\section{Outdoor Lighting Design for Washington DC, Tbilisi, and Polish Cities}

An AI system based on formal methods [16,17] was used to calculate the lighting designs. The designs are of higher quality than those provided by human designers. To prepare them, precise data on the infrastructure is needed: street geometries, lighting requirements (expressed in terms of lighting classes), the position of poles (on which lamps are placed), etc.

The data sources vary for the selected projects. In the case of Washington DC, we use the open data for pole locations [26], road shapes [27], and street segment details [28] (e.g., road classification). These data must be automatically verified by a set of consistency checks. As presented in Figure 8, there are initially 57,011 luminaries to consider, and during the data cleaning (cleaning and inference, function) 2865 poles were rejected-it is not known what exactly is illuminated by these luminaires-in such a case, they were subject to manual corrections (verification and cleaning function). For the 54,146 luminaries (clean inventory data object), the AI system creates the designs, which comply with the regulations. Approximately 40,500 luminaires are covered (the actual number of luminaires varies depending on the vendor being used; hence avg in Figure 8). The remaining cases cannot be carried out due to violation of the standards, namely poles being too far from each other, pole height being too short, etc. As our task is the estimation of the effectiveness of the lighting installation for a large, varied environment, we focus on the actual design for 40,500 luminaries. The final energy reduction is at $84 \%$. (There is a side observation regarding luminary efficiency: while preparing the designs for the same vendor but different release year models, namely 2018 and 2019, the latter is $2 \%$ more energy efficient; we use a conservative $1 \%$ for the estimation of the retrofit costs for year-to-year efficiency improvement, however.).

We faced a different situation in Tbilisi, Georgia. In this case, the inventory for the whole city was prepared by field survey teams. More than 91,000 poles were considered, and for all of them, the correct designs were delivered by the AI system. The main difference, in comparison with the Washington DC case, is a very small number of multiline roadways and large number of wide roads in the city, mainly in the old town. The presented design provides $68 \%$ energy consumption reduction. 


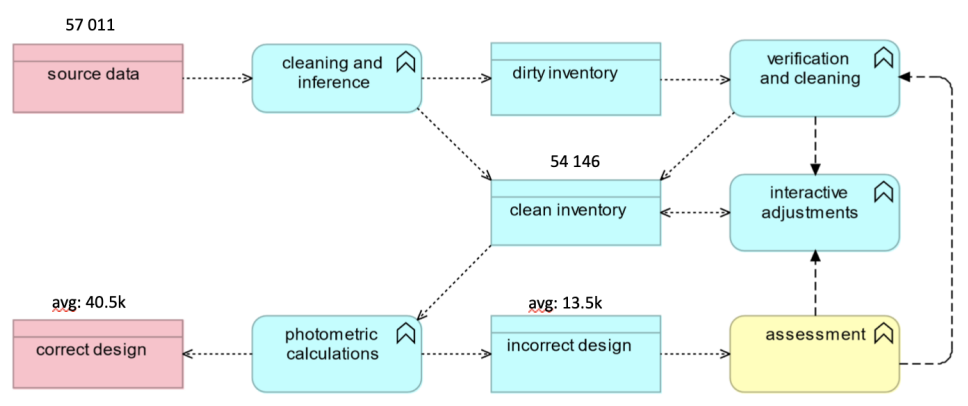

Figure 8. Data cleaning scheme.

The designs for six Polish cities were carried out in the second half of 2020. The efficiency assessment was made by comparing current electricity bills with planned retrofit. The areas under consideration are rather small: the largest is less than 10,000 luminaries, which coincides with lower expectations of the infrastructure owner regarding efficiency, usually in the range from $50 \%$ to $70 \%$. The optimized designs resulted in efficiencies of $61.46 \%, 74.40 \%, 76.28 \%, 77.84 \%, 81.69 \%, 84.00 \%$ energy consumption reduction.

The large-scale computations in the cases of Washington DC and Tbilisi took the AI system only a few hours, instead of weeks, as it would be in the case of human designers. Such a speedup enables efficiency comparison for different release year models and vendors or replacement strategies and further strategic investment planning. (The vendor optimization is not considered in the performed $L C O E$ calculations since such an optimization can violate public tender regulations, making it unrealistic.)

It needs to be pointed out that the AI-system-made designs are not only from $20 \%$ to $30 \%$ more efficient in terms of energy consumption reduction, but they also reduce up to $10 \%$ of the retrofit deployment cost, as compared to the average energy and investment costs efficiencies obtained from human made designs. The latter is caused by the fact that the luminaries with lower power are usually less expensive.

\section{Energy Generation Levelized Costs}

\subsection{Assumptions}

The calculation will depend on a number of parameters described below:

- $\quad$ size-area expressed in number of light poles;

- exchange_cost-average cost of exchanging one luminary that is the sum of the following costs:

- luminary_cost-average cost of one LED luminary;

- $\quad$ arm_cost_-average cost of one pole arm, which is exchanged with the luminary,

- install_cost-average cost of installation of one LED luminary with the arm replaced,

- efficiency - the retrofit efficiency evaluated as a percentage of the energy saved after retrofit; energy consumption after the retrofit compared with the consumption before the retrofit;

- init_power-the power of the original installation;

- trans_losses_-transmission losses in the energy grid;

- durability -durability of the installation;

- lum_trends_-trends in luminary prices.

\subsection{Calculation Method}

Street lighting is often the first or second largest local government energy consumption source, typically accounting for $25-50 \%$ of a municipal energy bill [29]. Transitioning from high-pressure sodium (HPS) to LED lamp technology can reduce this consumption by about $40 \%$. This value is guaranteed by nearly all luminary vendors. The rest of the reduction depends on the design quality. We will consider the final reduction by $40 \%$ (the 
lowest value that can be achieved by human designers) and also by $50 \%, 60 \%$, or more up to $80 \%$ for the designs made by AI software in our estimates. The levelized cost of energy is calculated by the following formula:

$$
L C O E=\frac{C A P E X+\sum_{t=1}^{\text {durability }} \frac{A_{t}}{(1+i)^{t}}}{\sum_{t=1}^{\text {durability }} \frac{M_{t, e l}}{(1+i)^{t}}}
$$

The CAPEX (capital expense) retrofit cost depends on the number of exchanged luminaries and their average exchange cost. One can notice that the exchange_cost slightly decreases when the quality of design grows, because a better design uses lower-power luminaries, which are less expensive. Finally, CAPEX is calculated as:

$$
\text { CAPEX }=\text { exchange_cost } t_{\text {efficiency }} * \text { size }
$$

where

$$
\text { exchange_cost } \text { efficiency }_{\text {exchange_cost }} *(1-(\text { efficiency }-50 \%) * 20 \%)
$$

Annual costs $A_{t}$ are equal to zero (as there is no cost of savings). Real interest rate $i$ in $\%$ is assumed to be $2 \%$.

Produced quantity of electricity $S A V_{t, e l}$ in the respective $t$ year is the same for all years and depends on two parameters: design quality and transmission losses in energy networks (we have to produce more energy than is consumed by luminaries), so:

$$
M_{t, e l}=\text { efficiency } *(1+\text { trans_losses }) * \text { init_power }
$$

Thus, the formula for the levelized cost of energy in the case of lighting retrofit simplifies as follows:

$$
\mathrm{LCOE}_{\text {ret }}=\frac{\text { CAPEX }}{S A V_{t, e l} * \sum_{t=1}^{\text {durability }} \frac{1}{(1+i)^{t}}}
$$

\subsection{Average CAPEX}

To assess the average cost of single luminary exchange, we have analyzed a set of Polish public tenders in 2020. The results are as follows:

- luminary_cost is estimated at EUR 177;

- $\quad$ arm_cost is estimated at EUR 47;

- $\quad$ install_cost is estimated at EUR 67.

This results in an average cost of exchanging a single luminary (exchange_cost) to be estimated at EUR 291.

Moreover, the luminary cost decreases with better design efficiency. The reason for this is that the more efficient design uses lower-power luminaries, which are less expensive. Our experience shows that every $5 \%$ increase in design efficiency decreases the luminary cost by $1 \%$. Table 2 presents the estimated CAPEX for the designs under consideration.

Table 2. CAPEX.

\begin{tabular}{ccccccc}
\hline CAPEX & Size & \multicolumn{5}{c}{ Design Efficiency } \\
\hline Where & & $40 \%$ & $50 \%$ & $60 \%$ & $70 \%$ & $11,30 \%$ \\
\hline Washington DC & 40,327 & $11,722,965$ & $11,605,735$ & $11,489,678$ & $11,374,781$ & $11,261,034$ \\
\hline Tbilisi, Georgia & 91,681 & $26,651,453$ & $26,384,939$ & $26,121,090$ & $25,859,879$ & $25,601,280$ \\
\hline Poland & 26,363 & $7,663,663$ & $7,587,026$ & $7,511,156$ & $7,436,044$ & $7,361,684$ \\
\hline average & 10,000 & $2,906,977$ & $2,877,907$ & $2,849,128$ & $2,820,637$ & $2,792,430$ \\
\hline
\end{tabular}




\subsection{Optimal OPEX Reduction}

To estimate one year saving $S A V_{i, e l}$ of the electricity, OPEX (operating expense) cost must be either calculated from known efficiency by comparing the bills before and after the retrofit, or actually designed with power settings for each of the luminaries.

In both cases we have to take into account not only the power of the installation but also the transmission losses. The losses vary from country to country. For example, to consume 1 MWh of energy we must produce 1038 MWh in Germany, 1059 MWh in US and $1058 \mathrm{MWh}$ in Georgia, as it is provided by the World Bank estimates [30].

In the aforementioned cases, Washington DC and Tbilisi, Georgia, the initial power before the retrofit was init_power ${ }_{W}=10.24 \mathrm{MW}$ and init_power $_{T}=16.32 \mathrm{MW}$, respectively. As the design efficiency varies from $50 \%$ (in case of human design) to $80 \%$ and even more for the AI system, the one-year savings are presented in Table 3 . Actual efficiency for the Washington DC and Tbilisi cases was $84 \%$ and $68 \%$ respectively.

Table 3. $S A V_{i, e l}$ in GWh.

\begin{tabular}{ccccccc}
\hline $\boldsymbol{S A} \boldsymbol{V}_{\boldsymbol{i}, \boldsymbol{e l}}$ & Size & \multicolumn{5}{c}{ Design Efficiency } \\
\hline Where & & $40 \%$ & $50 \%$ & $60 \%$ & $70 \%$ & $80 \%$ \\
\hline Washington DC & 40,327 & 18,095 & 22,619 & 27,143 & 31,667 & 36,190 \\
\hline Tbilisi, Georgia & 91,681 & 28,794 & 35,992 & 43,191 & 50,389 & 57,588 \\
\hline Poland & 26,363 & 5452 & 6815 & 8178 & 9541 & 10,904 \\
\hline average & 10,000 & 3292 & 4115 & 4938 & 5761 & 6585 \\
\hline
\end{tabular}

The annual saving is calculated as follows:

$$
\begin{gathered}
\text { OPT }=\text { hours_on } * \sum_{L \in \text { Luminaries }} \operatorname{Power}(l) \\
S A V_{i, e l}=(\text { init_power }-O P T) *(1+\text { trans_losses })
\end{gathered}
$$

where:

- hours_on is equal to $4170 \mathrm{~h}$, which is the lights on time per year;

- Luminaries is a set of luminaries used in the design and Power $(l)$ is the $l$ luminary power.

\section{5. $L C O E_{\text {retrofit }}$ Calculations}

The guarantee for luminaries is 10 years, but it is assumed that their life span is 15 years. Table 4 represents the $L C O E_{\text {retrofit }}$ for 15 years.

Table 4. 15 years $L C O E_{\text {retrofit }}$ in EUR.

\begin{tabular}{cccccc}
\hline LCOE & \multicolumn{5}{c}{ Design Efficiency } \\
\hline & $40 \%$ & $50 \%$ & $60 \%$ & $70 \%$ & $80 \%$ \\
\hline Washington DC & 50.42 & 39.93 & 32.94 & 27.96 & 24.22 \\
\hline Tbilisi, Georgia & 72.04 & 57.05 & 47.07 & 39.94 & 34.60 \\
\hline Poland & 109.39 & 86.64 & 71.48 & 60.65 & 52.54 \\
\hline average & 68.72 & 54.42 & 44.90 & 38.10 & 33.00 \\
\hline
\end{tabular}

We can see that in case of wide, multi-lane roads that dominate in Washington DC, the $L C O E$ is extremely low. In the case of narrower roads, mostly occurring in old cities, $L C O E$ is little worse but still not bad by comparison with other electricity sources.

We can also calculate $L C O E_{\text {retrofit }}$ for shorter duration, equivalent to the luminaire warranty period, which is conservative and safe; see Table 5 . 
Table 5. 10 year $L C O E_{\text {retrofit }}$ in EUR.

\begin{tabular}{cccccc}
\hline LCOE $_{\text {retrofit }}$ & \multicolumn{5}{c}{ Design Efficiency } \\
\hline & $40 \%$ & $50 \%$ & $60 \%$ & $70 \%$ & $80 \%$ \\
\hline Washington DC & 72.12 & 57.12 & 47.13 & 39.99 & 34.64 \\
\hline Tbilisi, Georgia & 103.04 & 81.61 & 67.33 & 57.13 & 49.49 \\
\hline Poland & 156.49 & 123.94 & 102.25 & 86.76 & 75.16 \\
\hline average & 98.30 & 77.85 & 64.23 & 54.50 & 47.21 \\
\hline
\end{tabular}

\section{Prediction}

Prediction of the $L C O E_{\text {retrofit }}$ is based on two assumptions:

- the price of the lamp is reduced by $1 \%$ per year,

- the efficiency of newly designed luminaries increases on average by $1 \%$ per year. (This is a rather conservative assumption, which comes from analysis of designs regarding the same areas, Washington DC in particular, using luminary models from 2018 and 2019; the efficiency of 2019 luminaries increased by about 2\% due to improvement of both LED technology and light distribution.).

The final prediction presented in Table 6 is based on 15 year duration. The initial values for this prediction were calculated as:

- MaxLCOE as LCOE for $40 \%$ energy reduction in small cities;

- MinLCOE as LCOE for $80 \%$ energy reduction in large, developed metropolises.

Table 6. Prediction of $L C O E$ in consecutive years in EUR.

\begin{tabular}{ccccc}
\hline Year & $\mathbf{2 0 2 0}$ & $\mathbf{2 0 2 5}$ & $\mathbf{2 0 3 0}$ & $\mathbf{2 0 3 5}$ \\
\hline Max LCOE & 109.39 & 98.73 & 89.10 & 80.42 \\
Min LCOE & 25.18 & 22.73 & 20.51 & 18.51 \\
\hline
\end{tabular}

The LCOEs for all considered designs were:

- Washington DC-84\% efficiency generated LCOE equal to 23.06 EUR/MWh,

- Tbilisi, Georgia-68\% efficiency generated LCOE equal to 40.70 EUR/MWh,

- for six Polish cities with efficiency in the range from $61 \%$ to $84 \%$ the LCOE was equal to 68.39 EUR/M, 56.80 EUR/MWh, 55.10 EUR/MWh, 54.00 EUR/MWh, 51.46 EUR/MWh, and 50.04 EUR/MWh, respectively. The weighted average efficiency for all designs is $76.93 \%$, and it generates LCOE equal to $54.64 \mathrm{EUR} / \mathrm{MWh}$.

Therefore, it seems that we can narrow the range between the minimum and maximum $L C O E_{\text {retrofit }}$ to $[23.06,54.64] \mathrm{EUR} / \mathrm{MWh}$. The prediction for this range is presented in Table 7.

Table 7. Prediction of LCOE in consecutive years in EUR, AI design

\begin{tabular}{ccccc}
\hline Year & $\mathbf{2 0 2 0}$ & $\mathbf{2 0 2 5}$ & $\mathbf{2 0 3 0}$ & $\mathbf{2 0 3 5}$ \\
\hline Max LCOE & 54.64 & 49.31 & 44.50 & 40.17 \\
Min LCOE & 23.06 & 20.81 & 18.78 & 16.95 \\
\hline
\end{tabular}

\section{Conclusions}

The cost of $1 \mathrm{MWh}$ electric energy generation is one of the most important factors when building new power plants. It varies from 37.1 to $137.9 \mathrm{EUR} / \mathrm{MWh}$ in the case of commercial green energy generation, without the cost of the energy storage, which multiplies it four times [1].

Development of modern lighting design methods based on formal methods and AI allows for quick, multi-scale calculations for large and diverse areas. The application of AI 
design tools shifts energy savings from a retrofit of the lighting system from $50 \%$ (in the case of human designers) to average $70 \%$. This results in $L C O E$ for retrofit, understood as cost of energy savings, to be in the range from 23.06 to 54.64 EUR/MWh. It is worth noting that it is NegaWatt energy that does not pose problems with transmission and storage. It also has a positive influence on the human health by reduction of light pollution, since the amount of generated light is minimized.

As a result, the lighting replacement based on effective, high-quality and optimized photometric designs should be recommended as a key solution in the field of renewable energy. This would be more ecologically and economically attractive than investment in new renewable energy sources.

The proposed approach of calculating $L C O E$ could also be applied to other domains of the energy market, especially those that require recurring upgrades with capital expense which lead to savings influencing operating expense. In addition to this, there has to be enough of a disruption to provide significant changes in operating expense. This is what the optimized outdoor lighting design provides in the presented case.

Author Contributions: Conceptualization, methodology, writing-original draft preparation, L.K.; investigation, S.S.; software A.B. and I.W.; writing-review and editing, I.W. All authors have read and agreed to the published version of the manuscript.

Funding: This research was funded by the AGH University of Science and Technology.

Institutional Review Board Statement: Not applicable.

Informed Consent Statement: Not applicable.

Data Availability Statement: Publicly available data have been cited accordingly.

Conflicts of Interest: The authors declare no conflict of interest.

\section{References}

1. Kost, C.; Shammugam, S.; Julch, V.; Nguyen, H.T.; Schlegl, T. Levelized Cost of Electricity Renewable Energy Technologies; Technical Report; Fraunhofer Institute for Solar Energy Systems ISE: Freiburg, Germany, 2018.

2. Green Paper-Policy Options to Accelerate the Global Transition to Advanced Lighting; Technical Report; United Nations Environment Programme (UNEP). 2014. Available online: https:/ / sdgs.un.org/publications/green-paper-policy-options-accelerate-globaltransition-advanced-lighting-17856 (accessed on 22 February 2021).

3. Wojnicki, I.; Kotulski, L.; Sędziwy, A.; Ernst, S. Application of Distributed Graph Transformations to Automated Generation of Control Patterns for Intelligent Lighting Systems. J. Comput. Sci. 2017. [CrossRef]

4. DIAL. DIALux Is the Software for Professional Lighting Design. Available online: https://www.dial.de/en/dialux/ (accessed on 25 February 2021).

5. Relux Informatik AG. Relux Desktop. Available online: https:/ / relux.com/en/relux-desktop.html (accessed on 25 February 2021).

6. Carli, R.; Dotoli, M.; Pellegrino, R. A decision-making tool for energy efficiency optimization of street lighting. Comput. Oper. Res. 2018, 96, 223-235. [CrossRef]

7. Carli, R.; Dotoli, M. A Dynamic Programming Approach for the Decentralized Control of Energy Retrofit in Large-Scale Street Lighting Systems. IEEE Trans. Autom. Sci. Eng. 2020, 17, 1140-1157. [CrossRef]

8. Sędziwy, A.; Kotulski, L.; Basiura, A. Multi-agent Support for Street Lighting Modernization Planning. In Proceedings of the 11th Asian Conference on Intelligent Information and Database Systems, ACIIDS, Yogyakarta, Indonesia, 8-11 April 2019. [CrossRef]

9. Beccali, M.; Bonomolo, M.; Lo Brano, V.; Ciulla, G.; Di Dio, V.; Massaro, F.; Favuzza, S. Energy saving and user satisfaction for a new advanced public lighting system. Energy Convers. Manag. 2019, 195, 943-957. [CrossRef]

10. Bonomolo, M.; Baglivo, C.; Bianco, G.; Maria Congedo, P.; Beccali, M. Cost optimal analysis of lighting retrofit scenarios in educational buildings in Italy. Energy Procedia 2017, 126, 171-178. [CrossRef]

11. Plebe, A.; Pavone, M. Multi-Objective Genetic Algorithm for Interior Lighting Design. In Machine Learning, Optimization, and Big Data; Nicosia, G., Pardalos, P., Giuffrida, G., Umeton, R., Eds.; Springer: Cham, Switzerland, 2018; pp. $222-233$.

12. Santiago, R.M.C.; Jose, J.A.; Bandala, A.A.; Dadios, E.P. Multiple Objective Optimization of LED Lighting System Design Using Genetic Algorithm. In Proceedings of the 2017 5th International Conference on Information and Communication Technology (ICoIC7), Melaka, Malaysia, 17-19 May 2017; pp. 1-5. [CrossRef]

13. Garces-Jimenez, A.; Castillo-Sequera, J.L.; Del Corte-Valiente, A.; Gómez-Pulido, J.M.; González-Seco, E.P.D. Analysis of Artificial Neural Network Architectures for Modeling Smart Lighting Systems for Energy Savings. IEEE Access 2019, 7, 119881-119891. [CrossRef] 
14. Lima, G.F.M.; Tavares, J.; Peretta, I.S.; Yamanaka, K.; Cardoso, A.; Lamounier, E. Optimization of Lighting Design Usign Genetic Algorithms. In Proceedings of the 2010 9th IEEE/IAS International Conference on Industry Applications-INDUSCON, Sao Paulo, Brazil, 8-10 November 2010; Voulme 8, pp. 1-6. [CrossRef]

15. Hidayat, I.; Utami, S.S. Activity Based Smart Lighting Control For Energy Efficient Building By Neural Network Model. E3S Web Conf. 2018, 43, 01017. [CrossRef]

16. Sȩdziwy, A. Sustainable Street Lighting Design Supported by Hypergraph-Based Computational Model. Sustainability 2016, 8, 13. [CrossRef]

17. Sędziwy, A.; Kotulski, L. Graph-Based Optimization of Energy Efficiency of Street Lighting. In Artificial Intelligence and Soft Computing; Rutkowski, L., Korytkowski, M., Scherer, R., Tadeusiewicz, R., Zadeh, L.A., Zurada, J.M., Eds.; Springer: Cham, Switzerland, 2015; pp. 515-526.

18. Wojnicki, I.; Kotulski, L. Improving Control Efficiency of Dynamic Street Lighting by Utilizing the Dual Graph Grammar Concept. Energies 2018, 130, 7402. [CrossRef]

19. Wojnicki, I.; Ernst, S.; Kotulski, L.; Sedziwy, A. Advanced Street Lighting Control. Expert Syst. Appl. 2014, 41, 999-1005. [CrossRef]

20. Sędziwy, A.; Basiura, A. Energy Reduction in Roadway Lighting Achieved with Novel Design Approach and LEDs. LEUKOS 2018, 14, 45-51. [CrossRef]

21. Basiura, A. Grafowy Model Formlany Wspólbieżnego Projektowania Oświetlenia Ulicznego. Ph.D. Dissertation, AGH University of Science and Technology, Kraków, Poland, 2020.

22. Sedziwy, A.; Kotulski, L. Multi-Agent System Supporting Automated Large-Scale Photometric Computations. Entropy 2016, 18, 76. [CrossRef]

23. Sędziwy, A.; Kotulski, L.; Basiura, A. Enhancing Energy Efficiency of Adaptive Lighting Control, Springer, Intelligent Information and Database Systems. In Proceedings of the 9th Asian Conference on Intelligent Information and Database Systems, ACIIDS, Kanazawa, Japan, 3-5 April 2017. [CrossRef]

24. Wojnicki, I.; Kotulski, L. Street Lighting Control, Energy Consumption Optimization. In Artificial Intelligence and Soft Computing; Lecture Notes in Computer Science; Springer: Cham, Switzerland, 2017; pp. 357-364.

25. Sędziwy, A. Effective Graph Representation Supporting Multi-agent Distributed Computing. Int. J. Innov. Comput. Inf. Control 2014, 10, 101-113.

26. Open Data. Street Lights, Washington DC. Available online: https://opendata.dc.gov/datasets/street-lights (accessed on 18 December 2020).

27. Open Data. Roads, Washington DC. Available online: https://opendata.dc.gov/datasets/roads-2015। (accessed on 18 December 2020).

28. Open Data. Street Segments, Washington DC. Available online: https://opendata.dc.gov/datasets/street-segments (accessed on 18 December 2020).

29. Ross, L. Reducing Energy Use in Public Outdoor Lighting. Available online: https://www.aceee.org/toolkit/2020/02/reducingenergy-use-public-outdoor-lighting (accessed on 25 February 2021).

30. The World Bank. Electric Power Transmission and Distribution Loseses; Technical Report; The World Bank, 2014. Available online: https: / / data.worldbank.org/indicator/EG.ELC.LOSS.ZS (accessed on 22 February 2021). 